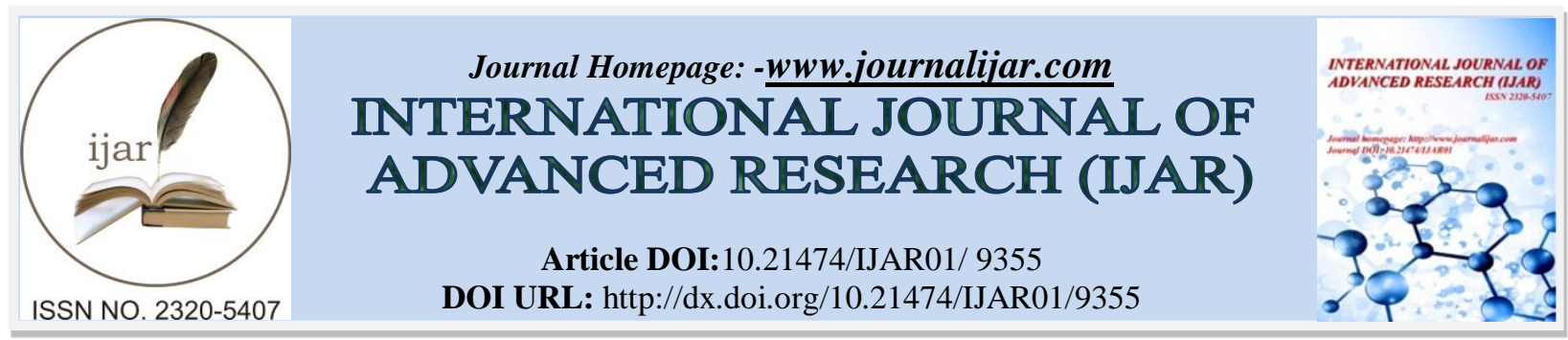

RESEARCH ARTICLE

\title{
EFFECT OF EXERCISE ON REDUCTION OF BODY FAT PERCENTAGE, BODY MASS INDEX AND WAIST CIRCUMFERENCE AMONG REGULAR GYM GOERS.
}

Muthukumaran Jothilingam ${ }^{1}$, M. Manikumar ${ }^{2}$, K. Kotteeswaran ${ }^{3}$, Jagatheesan Alagesan ${ }^{4}$ and P. Priyenka $^{5}$.

1. Muthukumaran Jothilingam Assistant Professor, Saveetha College of Physiotherapy, Saveetha Institute of Medical and Technical Sciences.

2. M.Manikuar, Associate Professor, Saveetha College of Physiotherapy, Saveetha Institute of Medical and Technical Sciences.

3. K.Kotteeswaran, Associate professor, Saveetha College of Physiotherapy, Saveetha Institute of Medical and Technical Sciences.

4. Jagatheesan Alagesan, Professor \& Principal, Saveetha College of Physiotherapy, Saveetha Institute of Medical and Technical Sciences.

5. B.P.T. Intern, Saveetha College of Physiotherapy, Saveetha Institute of Technical and Medical Sciences.

\section{Manuscript Info}

Manuscript History

Received: 06 May 2019

Final Accepted: 08 June 2019

Published: July 2019

Key words:-

exercise, BMI, Body Fat Percentage,

Waist Circumference.

\section{Abstract}

Aim \& Objective: To find out the effect of gyming on of body fat percentage, body mass index and waist circumference among regular gym goers.

Method: The regular new member list was obtained from the branch. On the basis of the list the first fitness test had been done and the values of their Body Mass Index, Body Fat Percentage and their Waist Circumference. Then after 6weeks from the date of first fitness test again their body mass index, body fat percentage and waist circumference was measured The two values were compared and concluded.

Outcome Measures: Body Mass Index- in $\mathrm{kg} / \mathrm{m}^{2}$ Body Fat - in percentage(\%), Waist Circumference- in Cms.

Result: The statistical analysis was done using paired t test and the calculated $\mathrm{p}$ value is significant for the pretest and post test values of $\mathrm{BMI}$ and waist circumference whereas the $\mathrm{p}$ value is not significant for the pretest and post test values of body fat percentage.

Conclusion: This study concludes that there is significant reduction in the body mass index and waist circumference after 6 weeks of regular gyming. But there is no significant change in the body fat percentage values.

Copy Right, IJAR, 2019,. All rights reserved.

\section{Introduction:-}

The Body Mass Index (BMI) or Quetelet index is a value derived from the mass (weight) and height of an individual. The BMI is defined as the body mass divided by the square of the body height, and is universally expressed in units of $\mathrm{kg} / \mathrm{m}^{2}$, resulting from mass in kilograms and height in meters. The BMI is an attempt to quantify the amount of tissue mass (muscle, fat, and bone) in an individual, and then categorize that person as 
underweight, normal, overweight or obese based on that value The Body Fat Percentage (BFP) of a human or other living being is the total mass of fat divided by total body mass; body fat includes essential body fat and storage body fat. Essential body fat is necessary to maintain life and reproductive functions. The percentage of essential body fat for women is greater than that for men, due to the demands of child bearing and other hormonal functions. The body fat percentage is a measure of fitness level, since it is the only body measurement which directly calculates a person's relative body composition without regard to height or weight. Waist measurement is a way to assess the fat deposition around the middle part of the middle. waist circumference is an indicator of internal fat deposits which coat the heart, kidney, liver, digestive organs and pancreas. It indicates the risk associated with the excess fat deposition. Obesity is a metabolic disorder. Obesity usually results from a combination of causes and contributing factors, including: Genetics. Genes may affect the amount of body fat that is stored, and where that fat is distributed. Genetics may also play a role in how efficiently body converts food into energy and how the body burns calories during exercise ${ }^{6}$. Family lifestyle: Obesity tends to run in families. If one or both of the parents are obese, then the child's risk of being obese is increased ${ }^{2}$. That's not just because of genetics. Family members tend to share similar eating and activity habits. Inactivity: If people not very active, they don't burn as many calories. With a sedentary lifestyle, they can easily take in more calories every day than thet burn through exercise and routine daily activities. Having medical problems, such as arthritis, can lead to decreased activity, which contributes to weight gain ${ }^{4}$. Unhealthy diet: A diet that's high in calories, lacking in fruits and vegetables, full of fast food, and laden with high-calorie beverages and oversized portions contributes to weight gain. Medical problems: In some people, obesity can be traced to a medical cause, such as Prader-Willi syndrome, Cushing's syndrome and other conditions Medical problems, such as arthritis, also can lead to decreased activity ${ }^{3}$, which may result in weight gain. Medications. Some medications can lead to weight gain if you don't compensate through diet or activity ${ }^{7}$. These medications include some antidepressants, anti-seizure medications, diabetes medications, antipsychotic medications, steroids and beta blockers. Social and economic issues: Research has linked social and economic factors to obesity. Avoiding obesity is difficult if there is no safe areas to exercise. Similarly, people may not have been taught healthy ways of cooking, or may not have money to buy healthier foods. In addition, the people they spend time with may influence your weight — more likely to become obese if they have obese friends or relatives. Age: Obesity can occur at any age, even in young children. But as age progresses, hormonal changes and a less active lifestyle increase the risk of obesity. In addition, the amount of muscle in body tends to decrease with age. This lower muscle mass leads to a decrease in metabolism. These changes also reduce calorie needs, and can make it harder to keep off excess weight.. Lack of sleep: Not getting enough sleep or getting too much sleep can cause changes in hormones that increase the appetiteGoing to gym and working out has become more common recently. The fitness industry is considered to include both fitness centers such as gyms as well as weight loss centers .Gyms use lots of equipment for cardio and weight training, with personal training available, racquetball maybe, and a pool. But this is an industry that has seen variety become the spice of life. Traditional exercises are being transformed into specialties and new programs are being developed at a breakneck pace. The health clubs keep updating its trainers and physiotherapists to make sure that the exercise techniques that they provide to their clients are at its best. Variations in the workouts are given daily so that it motivates their clients to workout with interest. Earlier going to gym was constrained to doing only cardio but now slowly trends are changing, functional training is becoming more popular. Number of clients who come to the health studio for losing weight is more. People choose gym as a option for losing their weight.

\section{Method:- \\ Study design: Prospective Study}

\section{Study Setting:}

O2 health studios, Chennai. Totally 100 sample were selected according to inclusion

\section{criteria:}

age above 18 years of both genders normal people with BMI value more than 23 subjects who have availed a regular gym package without any personal training .

\section{Procedure:}

The regular new member list was obtained from the branch. On the basis of the list the first fitness test had been done and the values of their Body Mass Index, Body Fat Percentage and their Waist Circumference. Then after 6weeks from the date of first fitness test again their body mass index, body fat percentage and waist circumference was measured .The two values were compared and concluded. 


\section{Outcome Measures:}

body mass index- in $\mathrm{kg} / \mathrm{m}^{2}$ body fat percentage- in percentage $(\%)$ was measured using four site skin fold caliper method. waist circumference- in $\mathrm{Cms}$ measured by using inch tape at mid way between xiphi sternum and umbilicus as reference point.

\section{Result:-}

The statistical analysis was done using paired $t$ test and the calculated $p$ value is significant for the pretest and post test values of BMI and waist circumference whereas the $p$ value is not significant for the pretest and post test values of body fat percentage.

\section{Discussion:-}

This study was done to find out the usefulness of going to a gym and doing exercises for a weight loss purpose. The study was carried out in the branches of a single health studio to maintain the uniformity of the pattern of exercises done by the participants. We made sure that the participants we include were regular to gym. One of the limitations was that we did not consider the diet aspects of the client. The results shows that there is no significant change in the fat percentage. This may be due to the diet differences. Diet plays an important role in reduction of body fat percentage. In future studies diet should also be considered. The number of hours of workout can also be considered. Some people workout for more than required hours and some people do not workout for adequate time. There is significant difference between the pre test and the post test values of Body Mass Index and waist circumference which is a positive. This shows that these clients have lost considerable amount of weight in 6 weeks' his study included the participants who followed a same pattern of exercises. The fitness field is updating the type of workouts that they give for their clients. Functional training is the latest trend to lose weights ${ }^{9}$. The benefits of functional training are believed to be high. The conventional exercises do not offer a dynamic pattern of exercising. In future studies the conventional exercise pattern and the functional training can be compared. Functional training is a nice topic of research interest. In future other aspects like age and gender can also be correlated..

\section{Conclusion:-}

This study concludes that there is significant reduction in the body mass index and waist circumference after 6 weeks of regular gyming. But there is no significant change in the body fat percentage values.

\section{Limitations:}

The study was done in a single health club. Factors like age and gender were not co-related.

\section{Future Recommendations:}

Age and gender can be co-related. Functional Training can be included

\section{Reference:-}

1. Lean ME, Han TS, Morrison CE. Waist circumference as a measure for indicating need for weight management. BMJ 1995; 311: 158-161.

2. Han TS, van Leer EM, Seidell JC, Lean ME. Waist circumference action levels in the identification of cardiovascular risk factors: prevalence study in a random sample. BMJ 1995; 311: 1401-1405.

3. Lemieux S, Prud'homme D, Bouchard C, Tremblay A, Despres JP. A single threshold value of waist girth identifies normal-weight and overweight subjects with excess visceral adipose tissue. Am J Clin Nutr 1996; 64: 685-693.

4. World Health Organization: Obesity and overweight. Fact sheet No. 311, updated March 2013

5. Australian Bureau of Statistics National Health Survey: Summary of results. ABS cat. no. 4364.0. 2004

6. Walls HL, Magliano DJ, Stevenson CE, Backholer K, Mannan HR, Shaw JE, Peeters A: Projected progression of the prevalence of obesity in Australia. Obesity. 2012, 20: 872-878.

7. Keys A, Fidanza F, Karvonen MJ, Kimura N, Taylor HL: Indices of relative weight and obesity. J Chronic Dis. 1972, 25: 329-343.

8. Pasco JA, Nicholson GC, Brennan SL, Kotowicz MA: Prevalence of obesity and the relationship between the body mass index and body fat: cross-sectional, population-based data. PLoS One. 2012, 7.

9. Romero-Corral A, Somers VK, Sierra-Johnson J, Thomas RJ, Collazo-Clavell ML, Korinek J, Allison TG, Batsis JA, Sert-Kuniyoshi FH, Lopez-Jimenez F: Accuracy of body mass index in diagnosing obesity in the adult general population. Int J Obes (Lond). 2008, 32: 959-966 
10. World Health Organization (WHO). Obesity: preventing and managing the global epidemic. Report of a WHO consultation. (1-253).World Health Organ Tech Rep Ser. 2000;894:i-xii.

11. Geneva: WHO; 2012. [accessed on November 28, 2012]. World Health Organization (WHO). World Health Statistics 2012

12. James WPT, Jackson-Leach R, Ni Mhurchu C, Kalamara E, Shayeghi M, Rigby NJ, et al. Overweight and obesity (high body mass index) In: Ezzati M, Lopez AD, Rodgers A, Murray CJL, editors. 